\title{
A synergistic antiproliferation effect of curcumin and docosahexaenoic acid in SK-BR-3 breast cancer cells: unique signaling not explained by the effects of either compound alone
}

Jeffrey D Altenburg ${ }^{1}$, Andrew A Bieberich², Colin Terry ${ }^{1}$, Kevin A Harvey ${ }^{1}$, Justin F VanHorn ${ }^{1}$, Zhidong Xu', $\checkmark$ Jo Davisson ${ }^{2}$ and Rafat A Siddiqui ${ }^{1,3,4^{*}}$

\begin{abstract}
Background: Breast cancer is a collection of diseases in which molecular phenotypes can act as both indicators and mediators of therapeutic strategy. Therefore, candidate therapeutics must be assessed in the context of multiple cell lines with known molecular phenotypes. Docosahexaenoic acid (DHA) and curcumin (CCM) are dietary compounds known to antagonize breast cancer cell proliferation. We report that these compounds in combination exert a variable antiproliferative effect across multiple breast cell lines, which is synergistic in SK-BR-3 cells and triggers cell signaling events not predicted by the activity of either compound alone.

Methods: Dose response curves for CCM and DHA were generated for five breast cell lines. Effects of the DHA+ CCM combination on cell proliferation were evaluated using varying concentrations, at a fixed ratio, of CCM and DHA based on their individual $\mathrm{ED}_{50}$. Detection of synergy was performed using nonlinear regression of a sigmoid dose response model and Combination Index approaches. Cell molecular network responses were investigated through whole genome microarray analysis of transcript level changes. Gene expression results were validated by RT-PCR, and western blot analysis was performed for potential signaling mediators. Cellular curcumin uptake, with and without DHA, was analyzed via flow cytometry and HPLC.
\end{abstract}

Results: CCM+DHA had an antiproliferative effect in SK-BR-3, MDA-MB-231, MDA-MB-361, MCF7 and MCF10AT cells. The effect was synergistic for SK-BR-3 (ER' $\left.\mathrm{PR}^{-} \mathrm{Her}^{+}\right)$relative to the two compounds individually. A whole genome microarray approach was used to investigate changes in gene expression for the synergistic effects of CCM+DHA in SK-BR-3 cells lines. CCM+DHA triggered transcript-level responses, in disease-relevant functional categories, that were largely non-overlapping with changes caused by CCM or DHA individually. Genes involved in cell cycle arrest, apoptosis, inhibition of metastasis, and cell adhesion were upregulated, whereas genes involved in cancer development and progression, metastasis, and cell cycle progression were downregulated. Cellular pools of PPAR $\gamma$ and phospho-p53 were increased by CCM+DHA relative to either compound alone. DHA enhanced cellular uptake of CCM in SK-BR-3 cells without significantly enhancing CCM uptake in other cell lines.

Conclusions: The combination of DHA and CCM is potentially a dietary supplemental treatment for some breast cancers, likely dependent upon molecular phenotype. DHA enhancement of cellular curcumin uptake is one potential mechanism for observed synergy in SK-BR-3 cells; however, transcriptomic data show that the antiproliferation synergy accompanies many signaling events unique to the combined presence of the two compounds.

\footnotetext{
* Correspondence: rsiddiqu@clarian.org

'Cellular Biochemistry Laboratory, Methodist Research Institute, Indiana

University Health, Indianapolis, Indiana, USA

Full list of author information is available at the end of the article
} 


\section{Background}

Breast cancer is now understood to be a collection of diseases characterized by malignant cells of different molecular phenotypes. Tumor subtypes are primarily categorized by expression of three cellular receptors: estrogen receptor (ER, HGNC gene symbol ESR1), progesterone receptor (PR, HGNC gene symbol PGR), and the epidermal growth factor receptor family member Her2/Neu (HGNC gene symbol ERBB2). Expression levels of all three cellular receptors are emerging as indicators of disease prognosis and criteria for determination of appropriate therapeutic regimen [1-5]. Because of this increased attention is being given to therapeutic strategies targeted to breast cancers based upon molecular subtypes [6-10]. Therefore, it should not be surprising that compounds exhibiting some utility as antiproliferation agents can show variable results when applied to cell lines of different ER/PR/Her2 phenotype. In fact, in an extensive characterization of the genetic and phenotypic variation among 51 breast cancer cell lines, Neve et al. even demonstrated variable potency of Trastuzumab among three Her2-overexpressing cell lines, with therapeutic response prediction later refined by post-hoc analysis of expression level for several other proteins and amplification of various chromosomal regions [11]. It stands to reason that investigation of anti-cancer dietary compounds will also benefit from a detailed look at interaction with cancer cell molecular phenotype. Only then will proper tailoring of dietary supplemental treatment to breast cancer subtype be facilitated. In this study we show that a combination of curcumin (CCM) and docosahexaenoic acid (DHA) results in variable antiproliferative effects across breast cancer cell lines of different molecular phenotype. For SK-BR-3, the cell line for which the effect is a synergistic improvement over either compound individually, the effect is accompanied by transcript and protein level changes that are not simply a combination of changes caused by either molecule alone.

DHA is an omega-3 fatty acid $\left(22: 6^{\Delta 4,7,10,13,16,19}\right)$, part of a family of compounds reputed to possess many human health benefits, including anticancer properties [12]. Early epidemiological evidence strongly linked fish oil (rich in DHA and eicosapentaenoic acid) with lowered incidence of several types of cancer, including breast cancer [13-16]. In addition to epidemiological studies, dietary studies with mice and humans, combined with numerous tissue culture studies, have substantiated the beneficial role of DHA in breast cancer [17-20]. DHA induces apoptosis in cancer cells through multiple mechanisms [21-27]. DHA also induces cell cycle arrest through p21-mediated inhibition of cyclindependent kinase-2 (CDK2) activity and stimulates protein phosphatase activity $[20,28]$. In addition, transport of DHA and other fatty acids to the nucleus and binding to nuclear receptors such as peroxisome proliferatoractivated receptor (PPAR) and retinoid $\mathrm{X}$ receptors (RXRs) have been reported. DHA is a general ligand of PPARs, but binds more selectively to RXR transcription factors [29]. RXRs form homo- or heterodimers with PPAR and other nuclear hormone receptor superfamilies that include receptors for steroids, thyroid hormones, retinoic acid and vitamin D. RXRs are in turn reported to regulate $\mathrm{p} 21$ expression in breast cancer MDA-MB-231 cells [30]. These recent developments suggest that DHA may also play a role in attenuation of breast cancer growth through a PPAR $\gamma / R X R-$ mediated mechanism. Finally, DHA down regulates CXCR4, indicating ability to reduce the metastatic potential of breast cancer cells by decreasing the surface expression of a pro-migratory molecule [31].

CCM [1,7-bis(4-hydroxy-3-methoxy phenyl) -1,6-heptadiene-3,5-dione] is a biphenyl compound naturally concentrated in the rhizome of the herb Curcuma longa, commonly known as turmeric in English, haldi in Hindi, and $u k o n$ in Japanese. CCM has been used in Asian medicine for over 3,000 years [32], and possesses a wide range of pharmacological activities including anti-inflammatory, anticancer, antioxidant, wound healing, and antimicrobial effects [33]. The pharmacology and putative anticancer properties of CCM have been extensively reviewed [34-38]. Preclinical studies have revealed chemopreventive potential of CCM for several cancers, including colon [39,40], duodenal [41], stomach [42], prostate [43], and breast [44]. CCM has been shown to block each step in the carcinogenesis process, namely tumor initiation, promotion, and progression [45]. CCM acts on multiple targets and inhibits activation of key cell signaling mediators, including $\mathrm{NF} \kappa \mathrm{B}(\mathrm{NF} \kappa \mathrm{B}), \mathrm{AP}-1$, Cox2, MMP9, PKC, and EGFR [38]. CCM dramatically induces transcription of PPAR $\gamma$ and activates PPAR $\gamma$ in hepatic stellate cells [39]. CCM regulates p21 expression through a p53-dependent pathway in several cellular models, including breast cancer cells [44,46-49]. CCM's antiproliferative effects, specifically on breast cancer cells, have been linked in multiple ways to the induction of apoptosis. For example, downregulation of c-Jun N-terminal kinase (JNK), upregulation of BAX as an effector of $\mathrm{p} 53$, downregulation of $\mathrm{Bcl}-2$, inhibition of $\mathrm{Akt} / \mathrm{PKB}$, and generation of reactive oxygen species (ROS) have all been observed in breast cancer derived cell lines exposed to curcumin [23,50-52].

It is clear that DHA and CCM independently have biological activities that warrant development for therapeutic purposes, and combinations of the two have even been reported to exert synergistic effects against colon cancer inflammation and growth of pancreatic tumor xenografts $[53,54]$. However, productive application of 
these two compounds in a breast cancer context requires: (1) comparison of cell lines representing distinct molecular phenotypes associated with disease subclasses, (2) quantitative methods for detection of synergy versus additive effects upon cell proliferation, and (3) molecular characterization of cellular response sufficient to show whether any detected synergy is based upon novel mechanisms versus a straightforward merger of effects expected of each molecule individually. Accordingly, this study included five breast cell lines covering distinct cellular receptor expression phenotypes: SK-BR3 (ER $\left.^{-} \mathrm{PR}^{-} \mathrm{Her}^{+}\right), \mathrm{MDA}-\mathrm{MB}-231$ (ER $\left.{ }^{-} \mathrm{PR}^{-} \mathrm{Her} 2^{-}\right)$, MDA-MB-361 (ER $\left.{ }^{+} \mathrm{PR}^{-} \mathrm{Her}^{+}\right)$, MCF7 (ER $\left.{ }^{+} \mathrm{PR}^{+} \mathrm{Her}^{-}\right)$ and MCF10AT $\left(\mathrm{ER}^{+}, \mathrm{PR}\right.$ isoform $\mathrm{B}$ but not A, Her2 variable) [11,55-58]. Across these cell lines, the antiproliferation effects of CCM, DHA, and a CCM+DHA combination were assessed quantitatively using methods designed specifically to detect the presence of synergistic versus additive or subadditive action. Detection of antiproliferation synergy for $\mathrm{CCM}+\mathrm{DHA}$ within the SK-BR3 cell line was followed by transcript analysis using the Agilent Whole Human Genome Microarray $4 \times 44 \mathrm{~K}$ platform, demonstrating a broad gene regulatory response across several functional categories that have little in common with transcript level changes caused by CCM or DHA alone. Two protein level phenomena that could be expected from CCM and DHA individually, PPAR $\gamma$ expression and p53 phosphorylation, were both increased in the presence of $\mathrm{CCM}+\mathrm{DHA}$ over levels observed for either compound alone. Finally, in addition to the combination causing novel intracellular molecular responses, DHA directly enhanced cellular uptake of CCM as demonstrated by flow cytometry and HPLC techniques. This suggests an added benefit of the combination in that, while DHA can achieve fairly high systemic concentration in humans, CCM on its own has limited bioavailability.

\section{Methods}

\section{Cell lines and reagents}

All cell lines were obtained from the American Type Culture Collections (ATCC; Manassas, VA) unless otherwise noted. MDA-MB-231, MDA-MB-361, and MCF7 cells were maintained in Dulbecco's modified eagle medium (DMEM; Invitrogen; Carlsbad, CA) supplemented with penicillin (100 units/ml), streptomycin $(100 \mu \mathrm{g} / \mathrm{ml})$ and $10 \%$ FBS. SK-BR-3 cells were maintained in McCoy's 5A medium (ATCC) supplemented with penicillin (100 units $/ \mathrm{ml})$, streptomycin $(100 \mu \mathrm{g} / \mathrm{ml})$ and $10 \%$ FBS. MCF10AT cells were purchased from Barbara Ann Karmanos Cancer Institute (Detroit, MI) and maintained in DMEM/F12 (Invitrogen; Carlsbad, CA) supplemented with penicillin (100 units/ml), streptomycin $(100 \mu \mathrm{g} / \mathrm{ml}), 5 \%$ horse serum, insulin $(10 \mu \mathrm{g} /$ $\mathrm{ml})$, epidermal growth factor $(20 \mathrm{ng} / \mathrm{ml})$, hydrocortisone $(0.5 \mu \mathrm{g} / \mathrm{ml})$, and cholera toxin $(100 \mathrm{ng} / \mathrm{ml})$. These supplemented media are referred to as complete media. All cell cultures were incubated in a humidified incubator at $37^{\circ} \mathrm{C}$ and $5 \% \mathrm{CO}_{2}$. The pan-caspase inhibitor Z-VADFMK was purchased from Biovision (Mountain View, CA). DHA (NuChek Prep, Inc., Elysian, MN) was diluted in $100 \%$ ethanol to make $50 \mathrm{mM}$ stock solutions. CCM (Sigma Aldrich, St. Louis, MO) was dissolved in DMSO to make $50 \mathrm{mM}$ stock solutions. Stock solutions of DHA and CCM were further diluted in respective media prior to cell treatment. Final concentration of ethanol or DMSO in treated cells was less than $0.1 \%$.

\section{Proliferation assays}

Cells were seeded into 96 well plates $\left(5 \times 10^{3} /\right.$ well $)$ in complete medium one day prior to treatment. For MDAMB-231, MDA-MB-361, and MCF7, treatments with DHA, CCM, or CCM+DHA were done in DMEM supplemented with $2 \%$ FBS. For SK-BR-3, treatments were done in McCoy's 5A medium supplemented with $2 \%$ FBS. For MCF10AT, treatments were done in complete medium. All cells were treated for 24 hours at $37^{\circ} \mathrm{C} / 5 \%$ $\mathrm{CO}_{2}$ with indicated concentrations of DHA,CCM or $\mathrm{CCM}+\mathrm{DHA}$ along with cells treated with similar concentrations of ethanol and/or DMSO (less than $0.1 \%$ ) as matching vehicle controls. Proliferation was analyzed using WST-1 assays in accordance with the manufacturer's instructions (Roche Biosciences, Indianapolis, IN).

\section{Analysis of synergy}

Proliferation results were analyzed as previously described [59] with some modification. Pilot assays were carried out individually for DHA and CCM with each cell line in order to determine $\mathrm{ED}_{50}$ for each reagent (Table 1). Using the ratio of the $\mathrm{ED}_{50} \mathrm{~s}$, the proportion of each compound needed in a combination dose was calculated with the constraint that each compound account for $50 \%$ of the combination's potency. As described by Tallarida, for each observed percent effect

Table $1 \mathrm{ED}_{50}$ values for DHA and curcumin effects on breast cancer cell lines

\begin{tabular}{lccc}
\hline & \multicolumn{2}{c}{ Initial $\mathrm{ED}_{\mathbf{5 0}}(\boldsymbol{\mu} \mathbf{M})^{\mathbf{a}}$} & $\begin{array}{c}\text { Combination } \\
\text { Ratio }(\boldsymbol{\mu} \mathrm{M})\end{array}$ \\
\cline { 2 - 4 } Cell Line & DHA & CCM & DHA:CCM \\
\cline { 2 - 4 } MCF7 & $56.5 \pm 8.2$ & $28.0 \pm 4.2$ & $55: 30$ \\
MCF10AT & $93.2 \pm 5.5$ & $45.8 \pm 2.5$ & $95: 45$ \\
MDA-MB-231 & $36.7 \pm 6.5$ & $34.7 \pm 10.4$ & $35: 35$ \\
SK-BR-3 & $63.8 \pm 1.5$ & $39.2 \pm 1.8$ & $60: 40$ \\
MDA-MB-361 & $52.5 \pm 9.5$ & $23.0 \pm 4.2$ & $50: 25$ \\
\hline
\end{tabular}

${ }^{a}$ Initial $\mathrm{ED}_{50}$ values calculated as mean \pm SD concentration required for $50 \%$ inhibition of proliferation from two independent triplicate assays. 
in the individual dose response curves, a theoretical additive dose was found [59]. Experiments were then carried out using the fixed ratio combination of DHA and CCM at a variety of different doses. For both individual compounds, the actual combination, and the theoretical additive doses, dose response curves were fit using GraphPad Prism (GraphPad Software Inc., La Jolla, CA). For each, a four-parameter dose response curve was fit using non-linear regression [60]. To evaluate the potential synergy between the compounds, the least squares fit line for the theoretical additive curve and the actual CCM+DHA mixture were plotted on the same axes, and the two curves were compared using parameter estimates and their respective 95\% confidence intervals. If the actual combination had a much different effect than expected, it was indicated by either a statistically significant shift in the $\mathrm{ED}_{50}$ or hillslope.

\section{Analysis of synergy by combination index (Cl)}

The Loewe additivity model was used as a second method of analyzing the interaction between DHA and CCM [61]. The interaction between the compounds is reported as the combination index in the following equation:

$$
C I=\left(d_{1} / D_{x, 1}\right)+\left(d_{2} / D_{x, 2}\right)
$$

In the equation, $\mathrm{d} 1$ and $\mathrm{d} 2$ represent the concentrations of the compounds in combination required to achieve $x$ effect. Dx, 1 and Dx, 2 represent the concentrations of the same compounds individually that would quantitatively achieve the same $x$ effect. A CI $<1.0$ indicates that the combination is synergistic, and a $\mathrm{CI}>1.0$ indicates an antagonistic interaction. The combination indexes for this study were determined by using concentrations corresponding to the $\mathrm{ED}_{50}$ of dose response curves for DHA, CCM or CCM+DHA.

\section{Cell culture and treatments for whole human genome transcript level analysis}

SK-BR-3 cells were plated in 6 well plates $\left(2.5 \times 10^{5} /\right.$ well) in complete medium overnight prior to treatment. Cells were treated with vehicle or with $30 \mu \mathrm{M}$ DHA, 30 $\mu \mathrm{M}$ CCM, or CCM+DHA $(12 \mu \mathrm{M} C \mathrm{CM}+18 \mu \mathrm{M}$ DHA $)$ for 24 hours with nine replicates per treatment. Following treatment, the cells were washed three times with PBS and suspended in $500 \mu \mathrm{l}$ Trizol Reagent (Roche Biosciences; Indianapolis, IN). The suspended cells were pooled in sets of three, resulting in triplicates for each condition. The samples were frozen at $-80^{\circ} \mathrm{C}$.

\section{Transcript level data collection and pre-processing}

Cells in Trizol were shipped on dry ice to Miltenyi Biotec Genomics Services (MBGS) for analysis via a one- color Agilent Whole Human Genome Oligo Microarray platform. RNA processing, array hybridization, image collection and data processing were executed according to protocols described in the MBGS Service Report. Briefly, total RNA was isolated using a standard Trizol protocol and evaluated for quality on an Agilent 2100 Bioanalyzer platform. Cy3-labeled cRNA was produced using the Agilent Low RNA Input Linear Amp Kit (Agilent Technologies) following the manufacturer's protocol. Yields of cRNA and the dye-incorporation rate were measured with the ND-1000 Spectrophotometer (NanoDrop Technologies). The hybridization procedure was performed according to the Agilent 60-mer oligo microarray processing protocol using the Agilent Gene Expression Hybridization Kit (Agilent Technologies) and Agilent's recommended hybridization chamber and oven. Microarray Cy3 images were read and pre-processed for background subtraction using Agilent's Feature Extraction Image Analysis Software (FES). Interchip scaling and differential gene expression calls were produced by analyzing FES-produced feature signal intensities with Rosetta Resolver (Rosetta Biosoftware). For each chip feature, significance of difference between control and experimental conditions was tested by applying an error model-based hypothesis test to all control replicates as a group versus each treatment replicate individually. Theory and validation of this method are described in Weng et al., 2006 [62]. The error model-based test results in a $\mathrm{P}$ value associated with the difference observed for each feature; difference values are reported as both $\log 10$ ratio and fold change of experimental signal intensity over control signal intensity.

\section{Processing of preselected candidate gene lists and gene ratio lists from MBGS}

Hypothesis tests from Rosetta Resolver were reported for all array features under each treatment condition; these results were further sorted by MBGS to produce files containing preselected candidate gene lists (PCGL) for all three replicates of each treatment condition. Each PCGL includes all array features returning a fold change $\geq 2$ (up or down) with an associated $\mathrm{P}$ value $\leq 0.01$. This does not unambiguously resolve all responses on a gene-by-gene basis as individual genes may be represented by multiple features within the Agilent array and that some individual genes could be represented by multiple features that returned contradictory responses. Therefore, the process of isolating genes with unambiguous transcript level responses required further logical filtering of the Rosetta Resolver results.

PCGL results for each experimental condition were filtered to return features showing fold change in the same direction in all three replicates. For these features, fold 
change and $\mathrm{P}$ value were averaged across the three replicates. All $P$ values are $\leq 0.01$, but for cases in which a gene is represented by multiple features responding in the same direction we used mean $\mathrm{P}$ value as a decision rule for which fold change value to attribute to the corresponding gene. These features were then sorted according to gene identity. Genes were subsequently filtered using a conditional formula that removed genes with contradictory features and, within each gene, returned fold change values associated with features exhibiting the smallest mean $P$ value.

We then constructed matrices of fold change values, allowing comparison of the responses of individual genes among treatments for the purpose of heatmap generation. Any gene that responded significantly to only one or two treatments required retrieving fold change values $<2.0$ from the whole-array gene ratio files. To do this, we assembled a cumulative list of Gene IDs including all genes that responded with fold change $\geq 2.0, \mathrm{P} \leq 0.01$, in at least one treatment. For a specific treatment, genes showing significant response were removed from the cumulative list, and remaining Gene IDs were used to query the whole-array gene ratio list for that treatment. In order to do this, gene ratio files from the three replicates of a treatment were combined, and means were calculated for the ratios and $P$ values of all features. The set of gene IDs was then used to extract relevant feature data from the set of averaged feature data. Finally, a set of fold change values and $\mathrm{P}$ values was assembled, for a treatment condition, showing both genes that responded to that treatment and values for genes that did not have significant responses $\geq 2.0$ in that treatment, but did in at least one of the other two treatments. This set of results supplied the values used to create the heatmap (see results section). Examples of the spreadsheets used to process the microarray data are available in the supplemental files (Additional file 1, 2, 3, 4, 5).

\section{Reverse transcript polymerase chain reaction}

SK-BR-3 cells were plated in 6 well plates $\left(2.5 \times 10^{5} /\right.$ well $)$ in complete medium overnight prior to treatment. Cells were treated with vehicle or with $30 \mu \mathrm{M}$ DHA, $30 \mu \mathrm{M}$ $\mathrm{CCM}$, or $\mathrm{CCM}+\mathrm{DHA}(12 \mu \mathrm{M} \mathrm{CCM}+18 \mu \mathrm{M} \mathrm{DHA})$ for 24 hours with nine replicates per treatment. Following treatment, the cells were washed three times with PBS and trypsinized. The cells were pooled in sets of three, resulting in triplicates for each condition. RNA was isolated using the RNeasy mini kit (Qiagen) according to manufacturer protocol. Complementary DNA was generated using Superscript III reverse transcriptase (Invitrogen) according to manufacturer protocol. PCR reactions were performed with 1 minute, $94^{\circ} \mathrm{C}$, followed by 30 cycles of $[1$ minute, $94^{\circ} \mathrm{C}$; 1 minute, $56^{\circ} \mathrm{C}$; 1 minute, $72^{\circ} \mathrm{C}$ ] followed by 5 minutes, $72^{\circ} \mathrm{C}$. Primers for PCR reactions are listed in table 2.
Table 2 Primers for PCR reactions

\begin{tabular}{|c|c|c|}
\hline Gene & Forward primer & Reverse primer \\
\hline CYP1A1 & 5'-ggactttaacccctacaggtatgt-3' & $\begin{array}{l}5^{\prime} \text {-ggatctttctctgtaccct } \\
\text { ggggtt-3' }\end{array}$ \\
\hline CYP1A2 & $\begin{array}{c}\text { 5'-cagaatgccctc } \\
\text { aacaccttctccatcg-3' }\end{array}$ & $\begin{array}{l}5^{\prime} \text {-gtgatgtcccggaca } \\
\text { ctgttcttg-3' }\end{array}$ \\
\hline CYP1B1 & $\begin{array}{c}5^{\prime} \text {-gagaacgtaccggcca } \\
\text { ctatcact-3' }\end{array}$ & $\begin{array}{l}\text { 5'-gttaggccacttca } \\
\text { gtgggtcatgat-3' }\end{array}$ \\
\hline SERPINB5 & $5^{\prime}-$ cttgcctgttccttttccac-3' & 5'-tggagagtttgaccttggca-3' \\
\hline CXCR4 & $5^{\prime}$-ggtggtctatgttggcgtct-3' & $5^{\prime}$-tggagtgtgacagcttggag-3' \\
\hline $15 s$ rRNA & 5'-ttccgcaagttcacctacc-3' & $5^{\prime}$-cgggccggccatgctttacg-3' \\
\hline
\end{tabular}

PCR products were visualized on $1 \%$ agarose gels. $15 \mathrm{~s}$ ribosomal RNA was used as a loading control.

\section{Western blot analysis}

SK-BR-3 cells were seeded into 6 well plates $\left(2.5 \times 10^{5} /\right.$ well) in complete medium one day prior to treatment. Following 24 hour treatments with $30 \mu \mathrm{M}$ DHA, $30 \mu \mathrm{M}$ $\mathrm{CCM}$, or a mixture containing $12 \mu \mathrm{M}$ CCM and $18 \mu \mathrm{M}$ DHA, the cells were lysed with RIPA lysis buffer containing pervanadate $(200 \mu \mathrm{M}), \mathrm{NaF}(1 \mathrm{mM})$, diisopropyl fluorophosphates (DIFP), and protease inhibitors (Roche Biosciences, Indianapolis, IN). Protein concentrations were normalized using $\mathrm{BCA}$ reagent according to the manufacturer's protocol (Pierce, Rockford, IL). SDSPAGE membranes were probed with antibodies to p21, p53 and phospho-p53 (Cell Signaling Technologies, Danvers, MA), PPAR $\gamma$ and GAPDH (Santa Cruz Biotechnologies, Santa Cruz, CA).

\section{Curcumin uptake}

The ability of each cell line to absorb CCM was quantified using flow cytometry. Cells were treated for 24 hours with escalating concentrations of CCM or combinations of DHA and CCM in McCoy's 5A with 2\% FBS at indicated concentrations. Cells were then trypsinized and washed three times with cold PBS. Because CCM exhibits a green fluorescent signal $[63,64]$, the cells were analyzed using the FL1 channel of a FACSCalibur flow cytometer (Becton Dickinson; Franklin Lakes, NJ) equipped with an air-cooled argon laser emitting at $488 \mathrm{~nm}$ wavelength. Fluorescence was detected through a $575 \pm 26 \mathrm{~nm}$ band pass filter and quantified using CellQuest Software (Becton Dickinson; Franklin Lakes, NJ). Quantification results are presented as percent increase of the mean fluorescence intensity of the CCM treated samples, compared to untreated controls in triplicate assays, using gated cell populations that exclude dead cells and cellular debris.

\section{Quantification of curcumin uptake by HPLC}

Quantification of CCM uptake by HPLC was performed to validate the flow cytometry method. Confluent cells 
in T75 flasks were treated with $20 \mu \mathrm{M}$ CCM for 24 hours. Following treatment, the cells were washed three times with cold PBS and lysed with RIPA buffer. The lysates were sonicated for 5 seconds. Cell lysate $(200 \mu \mathrm{l})$ and $20 \mu \mathrm{l}$ internal standard solution (R6G in ethanol, $300 \mu \mathrm{g} / \mathrm{ml}$ ) were added to a pyrex glass tube. Chloroform containing $0.05 \%$ BHT $(7 \mathrm{ml}), 3.5 \mathrm{ml}$ methanol containing $0.05 \%$ BHT and $1.7 \mathrm{ml} 0.5 \mathrm{M} \mathrm{KOAC-HAC}$ (1:1) buffer were added to the tube, vortexed for $1 \mathrm{~min}$ ute, and centrifuged at $900 \times \mathrm{g}$ for $10 \mathrm{~min}$. The chloroform layer was harvested and dried under nitrogen gas flow. The residue was dissolved in $200 \mu \mathrm{l}$ ethanol and transferred to an HPLC sample vial. CCM uptake was analyzed by a reversed-phase HPLC method using a Shimadzu LC-20AT HPLC system equipped with a multiwavelength diode array detector (DAD), a SIL-20AC $\mathrm{H}_{\mathrm{HT}}$ autosampler, and an Ascentis ${ }^{\mathbb{B}} \mathrm{C} 18$ column $(4.6 \times 250$ $\mathrm{mm}, 5 \mu \mathrm{m}$ ) (Supelco, Sigma-Aldrich; St. Louis, MO). A gradient mobile phase composed of $45 \%$ acetonitrile (0.1\% TFA)-55\% water (0.1\% TFA) to $100 \%$ acetonitrile $(0.1 \%$ TFA) was used. The flow rate was $1.0 \mathrm{ml} / \mathrm{min}$ and the detection wavelengths were $426 \mathrm{~nm}$ and $528 \mathrm{~nm}$, respectively, for CCM and rhodamine $6 \mathrm{G}$ (internal standard). The CCM peak was identified by comparing to the reference standard, and the quantification of the CCM was preceded with an external standard curve combined with internal standard technology. The concentration of the CCM was normalized based on the protein concentration of the cell lysate.

\section{Statistics}

Statistical analysis of data is described earlier for each specific experiment. Otherwise all comparisons were analyzed by ANOVA. P values less than 0.05 were considered significant. Triplicate experiments were repeated at least three times.

\section{Results}

DHA and curcumin exert synergistic anti-proliferative effects on SK-BR-3 cells

Initial cell proliferation assays were performed with dilution series $(0-100 \mu \mathrm{M})$ of DHA and CCM using four breast cancer cell lines and one line (MCF10AT) representing 'premalignancy', each with a unique pattern of cellular receptor expression: SK-BR-3 (ER $\left.{ }^{-} \mathrm{PR}^{-} \mathrm{Her} 2^{+}\right)$, MDA-MB-231 (ER- PR $^{-}$Her2-), MDA-MB-361 (ER ${ }^{+}$PR $^{-}$ Her2 $\left.{ }^{+}\right)$, MCF7 $\left(\mathrm{ER}^{+} \mathrm{PR}^{+} \mathrm{Her}^{-}\right)$and MCF10AT $\left(\mathrm{ER}^{+}\right.$, $\mathrm{PR}$ isoform $\mathrm{B}$ but not $\mathrm{A}, \mathrm{Her} 2$ variable). $\mathrm{ED}_{50}$ values were determined for DHA and CCM, for each cell line, and presented in Table 1. A combination of CCM+DHA (with proportions of DHA and CCM derived from their $\mathrm{ED}_{50}$ values) was used to measure the antiproliferation effect for each cell line at different doses $(0-100 \mu \mathrm{M})$ as described by Tallarida [59]. The dose response curve for
$\mathrm{CCM}+\mathrm{DHA}$ was then compared to the theoretical additive dose response curve to determine if the combination of $\mathrm{CCM}+\mathrm{DHA}$ resulted in a synergistic effect. It can be seen that the combination of CCM+DHA (2:3 ratio) when used below $50 \mu \mathrm{M}$ exerted a synergistic effect only in the SK-BR-3 breast cancer cell line (Figure $1 \mathrm{~A})$. While there was no substantial difference in $\mathrm{ED}_{50}$ values, there was a significant difference in the hillslopes $[(-7.6 ; 95 \%$ CI $(-10.2,-5.1)$ for the theoretical additive curve and -1.9 ; $95 \%$ CI $(-2.8,-1.0)$ for the actual mixture)]. This indicates that the span of doses where the actual combination of CCM+DHA is effective is much greater than expected. The synergism between DHA and CCM disappeared at higher doses, though a dosedependent antiproliferative effect was still present. CCM +DHA also affected the MDA-MB-231, MDA-MB-361, MCF7, and MCF10AT cell lines, but subadditive to additive results were observed at all combinations tested (Figure 1B-E). Extending the treatments to 48 hours had no significant effect on the synergistic or subadditive status of each cell line (data not shown). The synergistic effect of CCM+DHA on SK-BR-3 cells was further confirmed using an alternative approach of calculating the Combination Index. The combination of $\mathrm{CCM}+\mathrm{DHA}$ at concentrations below $50 \mu \mathrm{M}$ had a Combination Index $<1$, indicating synergism between two compounds (Figure $2 \mathrm{~A}$ ). We further experimentally compared antiproliferative effects of the combination with each compound individually using an optimal concentration $(30 \mu \mathrm{M})$ and found that neither DHA or CCM were effective in inhibiting cell growth, whereas $30 \mu \mathrm{M}$ of the combination $(18 \mu \mathrm{M}$ DHA $+12 \mu \mathrm{M}$ CCM $)$ significantly inhibited SK-BR-3 cell growth (Figure 2B).

\section{DHA + Curcumin regulatory effects on genes of disease- relevant functional groups}

Transcript level changes were assessed for three replicate SK-BR-3 cell populations for each of three 24 hour treatment conditions: CCM $(30 \mu \mathrm{M})$, DHA $(30 \mu \mathrm{M})$ and $\mathrm{CCM}+$ DHA $(12 \mu \mathrm{M}+18 \mu \mathrm{M})$. The Agilent whole human genome microarray results for each of the three treatment conditions were compared with transcript levels for SK-BR-3 cells left untreated in growth medium for 24 hours. As described in Methods, Rosetta Resolver was used to assign $\mathrm{P}$ values to individual chip elements for differences between untreated and treated cells using an error model-based hypothesis test. All chip elements meeting the criteria of fold-change $\geq 2.0$ $(\mathrm{p}<0.01)$, in any experimental replicate, were further filtered to return only transcripts for which at least one chip element responded with 2-fold or greater change, in the same direction, $\mathrm{p}<0.01$, with no other chip element indicating a significant contradictory directional change, across all three replicates for a treatment. 
According to these criteria, the numbers of transcripts exhibiting significant change for each treatment are as follows: CCM, 8,817; DHA, 61; CCM+DHA, 1,449 (Additional file 6).

The most striking initial result was that $\mathrm{CCM}+\mathrm{DHA}$ caused far fewer significant transcript level changes in SK-BR-3 cells than CCM alone, even though CCM + DHA had a greater antiproliferative effect. A cursory examination of the data also showed that some of the transcripts responding to CCM+DHA did not appear as significant responders in either of the other two treatments. Therefore, our strategy for an initial informatic analysis of these data was to rank CCM+DHA responders by magnitude of change, place a minimum cutoff at 5-fold (up or down), and annotate genes appearing within this set according to known disease-relevant functions. In addition, CCM+DHA responders below 5fold were scanned for genes of known relevance to antiproliferation processes, such as caspases. Figure 3 illustrates the results in the form of a heatmap divided into functional blocks. This strategy recovered an interesting picture showing 31 functionally diverse transcript regulatory responses, many of which are unique to the CCM + DHA combination. We observed that genes involved in tumor progression/growth, cell cycle progression, metastasis, and anti-apoptosis/survival were synergistically downregulated by the combination, while genes involved in apoptosis, tumor suppression, and inhibition of metastasis were synergistically upregulated. Interestingly, we also found a group of cytochrome p450 genes (1A1, 1A2, 1B1), which are involved in enhancement of anti-cancer effects of small molecules, including some dietary compounds (see discussion below). Results from the microarray transcript analysis were further validated by RT-PCR for selected genes, and our results (Figure 3B) have validated changes observed within the microarray data. RT-PCR also confirmed that CYP1A1/CYP1A2 and CXCR4 did not respond to DHA or CCM alone, but their expression was stimulated or reduced, respectively, by combined DHA+CCM treatment (Figure 3B). Similarly, RT-PCR data also verified other directional changes indicating that the CCM effect on CYP1B1 was reversed by CCM+DHA, whereas SERPINB5 expression was enhanced following $\mathrm{CCM}+\mathrm{DHA}$ treatment. While it is important to confirm expression levels of proteins directly before concluding specific signaling mechanisms, the genome-wide study of transcript and protein level correlation by Shankavaram et al. demonstrates predictive power of transcripts for protein levels across the NCI60 cell line panel[65]. Therefore, as a hypothesis building tool, transcript screens serve as valuable indicators of relevant network areas to study further.

SERPINB5 and CYP1A1/1A2/1B1 are transcripts of special functional interest. SERPINB5 produces a protein 

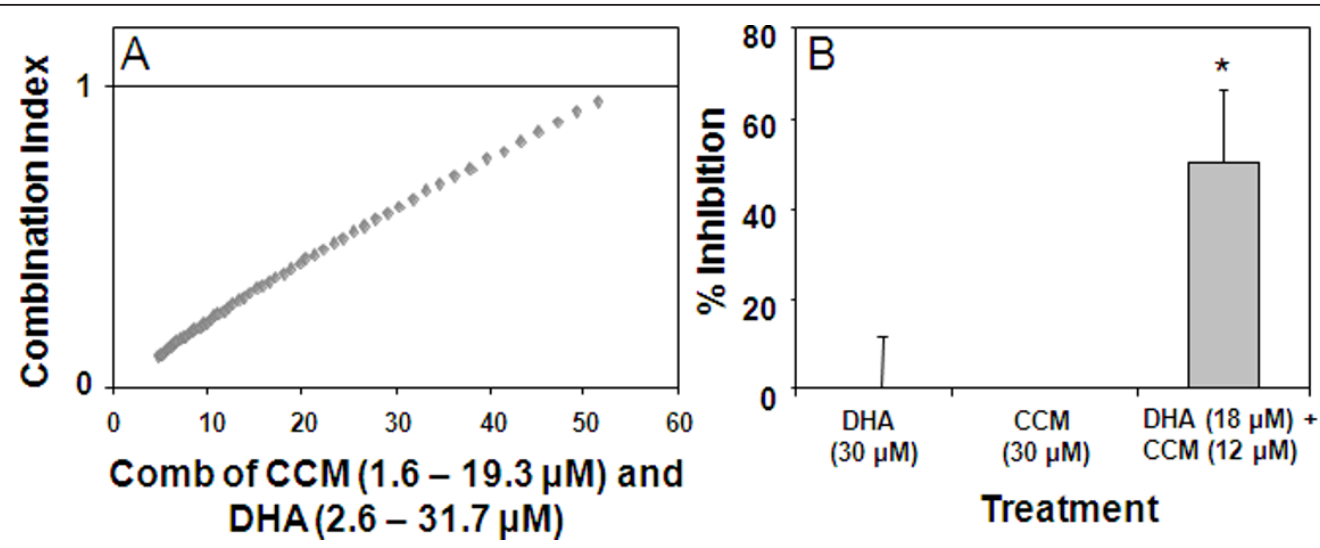

\section{Treatment}

Figure 2 The synergistic effect of CCM+DHA on SK-BR-3 proliferation. (A) Combination index (CI) calculated for the SK-BR-3 cell proliferation. (B) Direct comparisons of $30 \mu \mathrm{M}$ treatments with CCM and DHA individually with $30 \mu \mathrm{M}$ treatment using the 2:3 ratio CCM+DHA combination. $\mathrm{P}<0.05$ for three triplicate experiments.

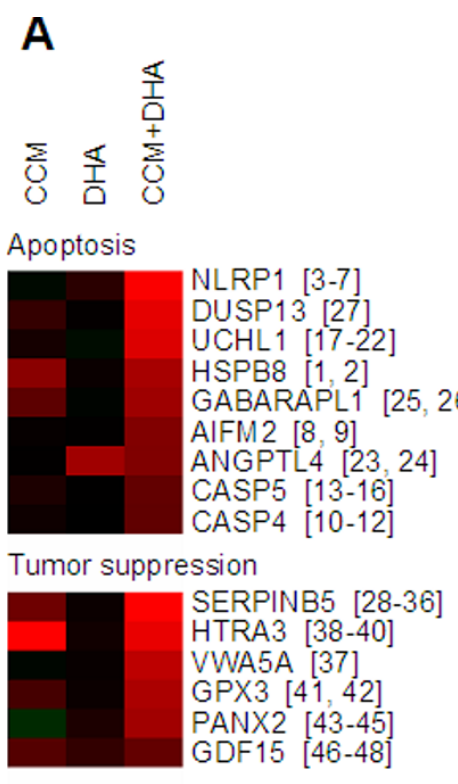

Anti-metastasis

MAP2 [49-51]

Small molecule enhancement

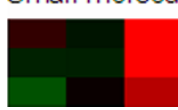

CYP1A2 [52, 55

CYP1B1 $[52,56-58,59]$

$$
\underset{0}{\frac{1}{1}} \frac{\frac{\pi}{1}}{0}
$$

Tumor progression/growth

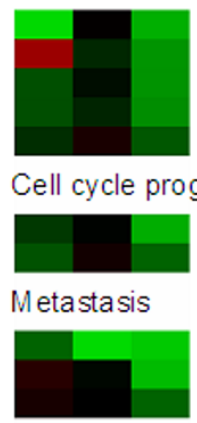

DOCK2 [61, 62]

CCL5 [63-68]

SLC39A4 [60]

CCL2 [67]

Cell cycle progression

MCM7 [75-77]

SEPT6 $[73,74]$

\section{Metastasis}

\section{GSC [78]}

CXCL1 [79-83]

CXCR4 [84-86]

Anti-apoptosis/cell survival

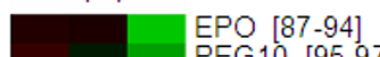

ETV1 [69-72]
B

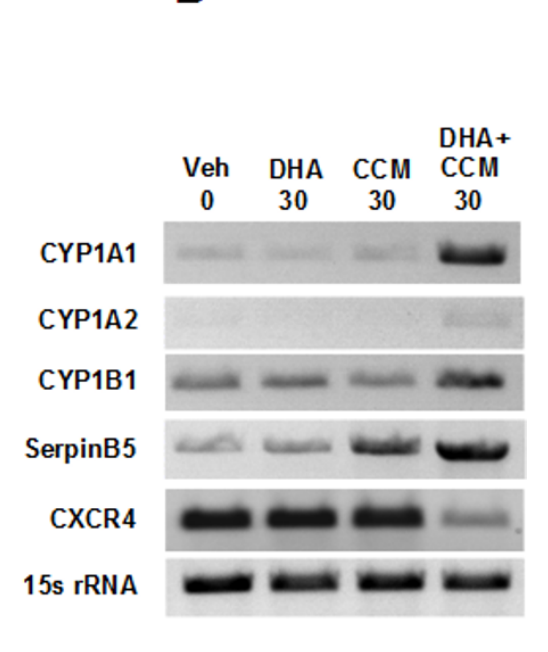

PEG10 [95-97]

Figure 3 Transcripts of functional importance relative to the synergistic antiproliferative effect of the curcumin/DHA combination. (A) All genes are labeled according to current HGNC symbols. Numbers to the right of gene symbols indicate references in a separate transcript annotation bibliography (see Additional file 8). Fold-change and associated P values corresponding to this figure can be found in Additional file 9. Heatmap values are $\log _{2}$-transformed, normalized fluorescence ratios for untreated versus treated cells (see methods), with green indicating upregulation and red indicating downregulation relative to untreated SK-BR-3 cells. All responses shown for DHA+CCM were 2-fold or greater, $\mathrm{p}$ $<0.01$, on three replicate arrays. For the purpose of visual comparison within a heatmap format, values for non-significant responses are mean normalized fluorescence ratios from three replicate arrays. For genes represented by more than one chip feature in the Agilent platform, mean normalized fluorescence ratio was retrieved for the feature producing the lowest mean $\mathrm{P}$ value. As such, some responses in this figure appear greater than 2-fold but were not significant according to the criterion $p<0.01$. (B) RNA was isolated from SK-BR-3 cells treated with $30 \mu M$ DHA, $\mu \mathrm{M} C \mathrm{CCM}$, or a mix of $12 \mu \mathrm{M} C \mathrm{CM}+18 \mu \mathrm{M}$ DHA. RT-PCR was performed for selected genes in order to validate the microarray data. Results are representative of three separate experiments. 
also known as maspin, and is thought to be a major downstream effector for the tumor suppression effect of Tamoxifen [66-68]; therefore, it is possible that CCM + DHA modulates a pathway overlapping that of Tamoxifen. CYP1A1/1A2/1B1 are members of the cytochrome P450 family. They are thought to enhance the anticancer effects of some small molecules, including dietary compounds, by metabolizing them into other structures with additional antiproliferative effects [69-72].

\section{CCM+DHA effects are mediated through an apoptotic process}

As shown above, our data clearly indicated an induction of genes involved in apoptosis. In order to further validate contribution of apoptosis to the reduction of cell proliferation during $\mathrm{CCM}+\mathrm{DHA}$ treatment, we used a pan-caspase inhibitor (Z-VAD-FMK) to inhibit initiation of the apoptotic process. Data shown in Figure 4 indicate that CCM and DHA, in varying concentrations of a fixed 2:3 ratio, inhibited cell proliferation in a dose dependent manner $(20-90 \mu \mathrm{M})$, and the pan-caspase inhibitor significantly reduced the effect of CCM+DHA at all concentrations tested.

\section{Protein level mediators of CCM+DHA synergistic effect}

One common mediator for DHA and CCM is the cell cycle regulator $\mathrm{p} 21$. In contrast to our prediction, we found that DHA and CCM alone or in combination do not increase p21 protein expression in SK-BR-3 cells (Figure 5A), but can increase p21 in the MDA-MB-231 cell line (data not shown). As mentioned in the

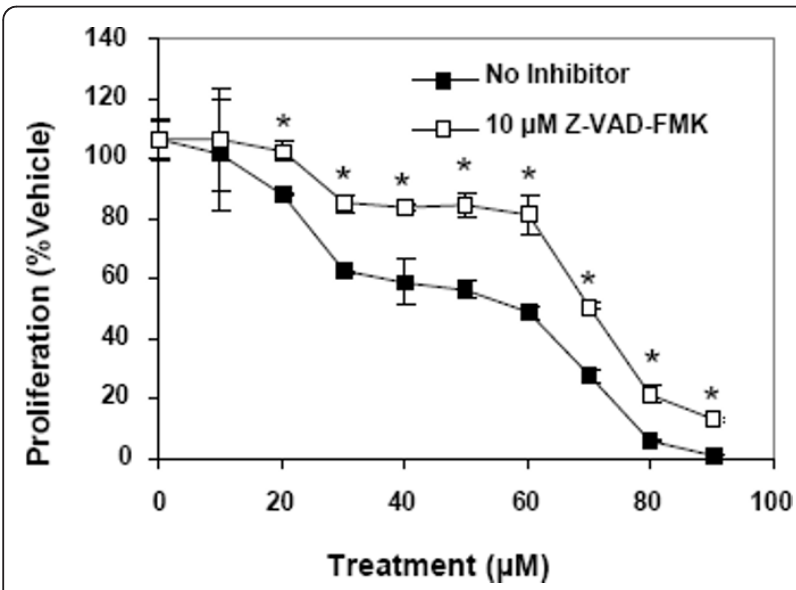

Figure $4 \mathrm{CCM}+\mathrm{DHA}$ inhibit proliferation through a caspasemediated process. SK-BR-3 cells were pretreated for one hour with $20 \mu \mathrm{M}$ Z-VAD-FMK, a pan-caspase inhibitor, prior to the addition of escalating doses of CCM+DHA (2:3 ratios). After 24 hour incubation, proliferation was analyzed with WST-1 reagent according to manufacturer protocol. Results are representative of three separate triplicate experiments. ${ }^{*} \mathrm{P}<0.05$ for Student's t-tests comparing the treatments with or without the pan-caspase inhibitor. introduction, CCM has been previously reported to affect p53 activity, and DHA is known to be a ligand for PPAR $\gamma$; therefore, we investigated the roles of expression and activation for p53 and PPAR $\gamma$ by DHA, CCM or the combination relative to their synergistic growth inhibitory effects. We observed that treating SK-BR-3 cells with $30 \mu \mathrm{M} C \mathrm{CM}+\mathrm{DHA}$ (2:3 ratio) resulted in increased phosphorylation of p53 and increased expression of PPAR $\gamma$ (Figure 5A). These increases were not detected when the cells were treated with $30 \mu \mathrm{M}$ DHA alone, and the effects were lower with $30 \mu \mathrm{M}$ CCM alone. Increases in p53 phosphorylation and PPAR $\gamma$ expression were not observed in MCF7 cells with identical treatments (Figure $5 \mathrm{~B}$ ), suggesting that the effects are specific for the SK-BR-3 cell line. When treated with a dilution series of either DHA or CCM alone, phosphorylation of p53 and upregulation of PPAR $\gamma$ only occurred with CCM treatment (Figure $5 \mathrm{C}$ ), which suggests that the DHA portion of the combination enhanced CCMmediated effects through the p53 and PPAR $\gamma$ pathway.

\section{Effects of DHA on curcumin uptake}

While the mechanism of CCM entry into cells is unknown, we have analyzed the differences among four breast cancer cell lines for ability to absorb CCM. We quantified CCM uptake by flow cytometry as CCM is known to fluoresce in the green band $[63,64]$. In order to validate the flow cytometry results, HPLC analysis was also performed concurrently with initial flow cytometry experiments (Figure 6A-B). The flow cytometry data match trends seen in the HPLC results, but with smaller dynamic range. SK-BR-3 cells treated with 20 $\mu \mathrm{M}$ CCM absorbed four-fold greater levels of CCM than the MCF7 cells and 10-fold greater levels than the MDA-MB-231 and MDA-MB-361 cells (Figure 6C). Combining DHA with CCM further enhances the CCM absorption of SK-BR-3 cells without significantly enhancing CCM uptake in the other cell lines (Figure 6C). This suggests that DHA enhancement of cellular permissiveness for CCM absorption is a potential mechanism for the increased antiproliferative effects. It should be noted that both HPLC and flow cytometry do not distinguish CCM taken into the cell from CCM that is bound to the cell surface. However, it is clear that the SK-BR-3 cells exhibit a higher level of CCM fluorescence than the other cell lines and that the fluorescence is increased in the presence of DHA. When viewed with the data describing antiproliferative effect and molecular level changes, it is unlikely that these data reflect only CCM on cell surfaces.

\section{Discussion}

The idea that changes in diet or diet supplementation may improve the health of cancer patients or enhance 


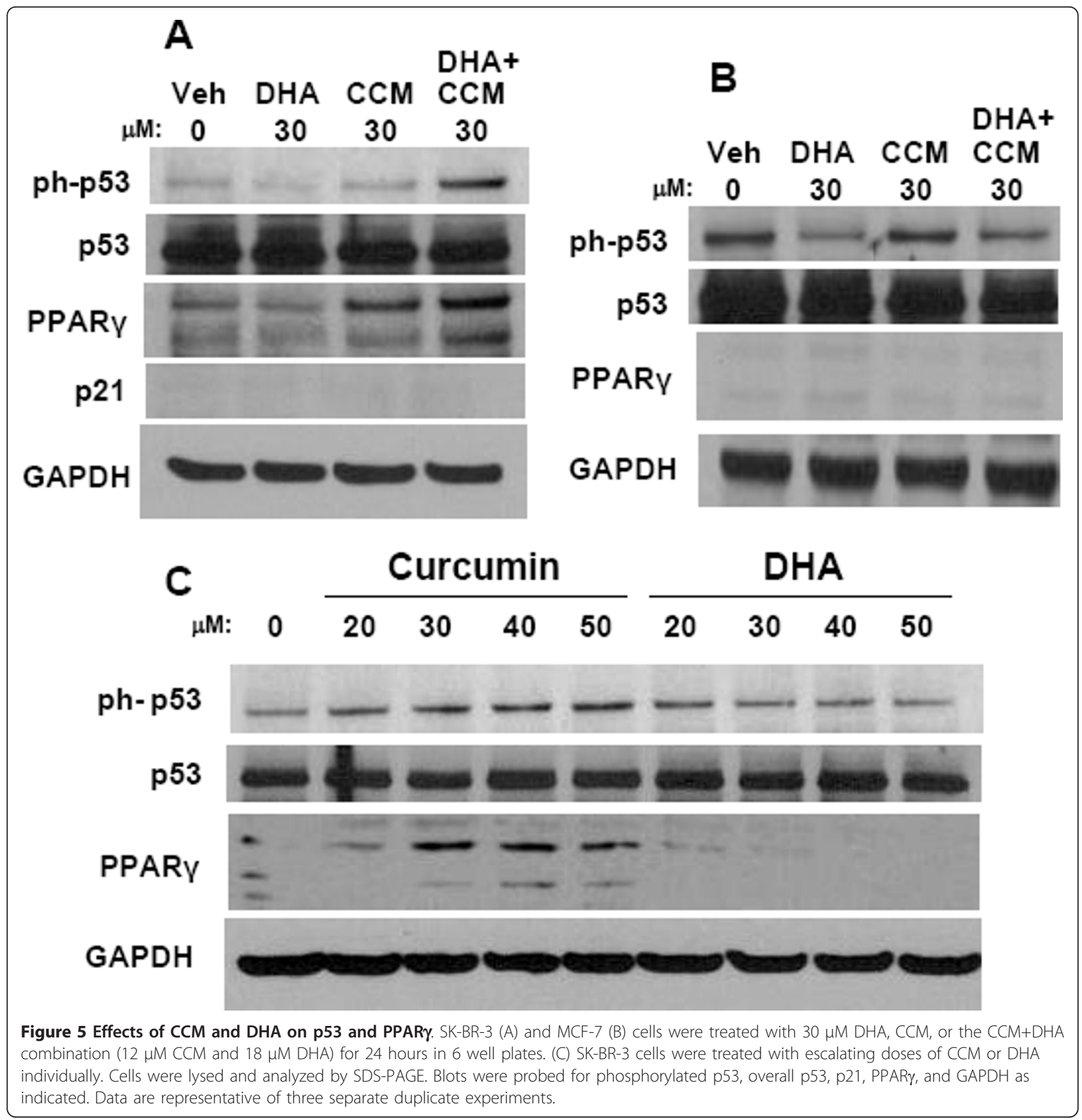

the effectiveness of existing treatments is a compelling motivation for exploring the activities of dietary compounds. The translational process for such molecules benefits from a relative lack of toxic side effects and source material that is inexpensive and easily accessible relative to synthetic pharmaceuticals. Human diets can routinely encompass many biologically active small molecules, and evidence for synergy between dietary compounds is emerging $[53,54,73]$. In this study we have presented data demonstrating that at low concentrations, a combination of the omega-3 PUFA, DHA, and curcumin, a molecule found in turmeric, exerts a synergistic antiproliferative effect on the estrogen receptor negative, HER-2 positive SK-BR-3 breast cancer cell line. The degree of synergy decreased, relative to activity of each compound alone, as concentration of the CCM+DHA combination was increased, though total anti-proliferative effect continued to increase with concentration. This observation has also been made by others reporting synergy between DHA 

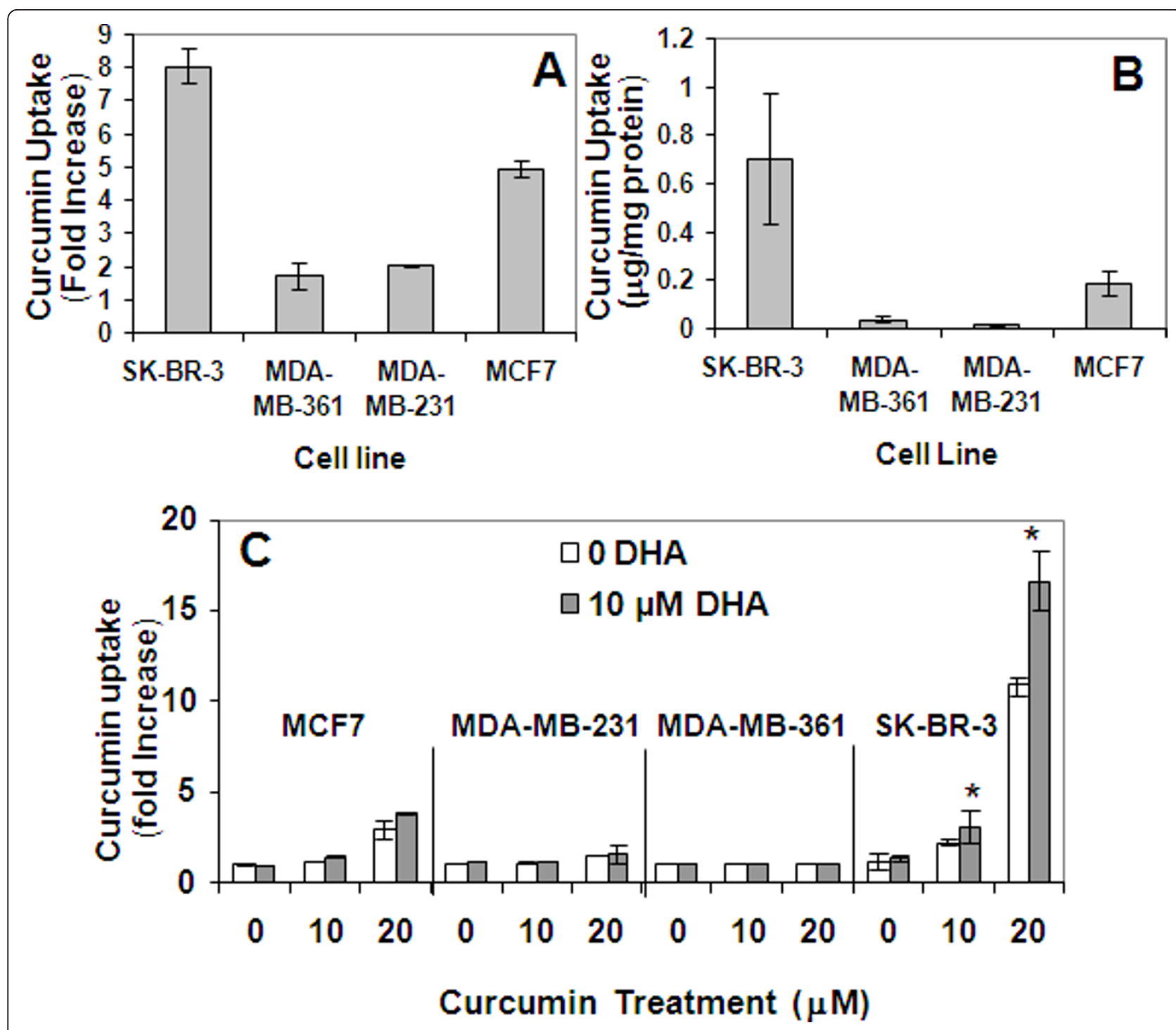

Figure 6 Effect of DHA on CCM uptake. Cells were treated with $20 \mu \mathrm{M}$ CCM for 24 hours. CCM uptake was quantified by flow cytometry (A) in comparison with HPLC (B) as described in Materials and Methods. (C) SK-BR-3, MDA-MB-231, MDA-MB-361, MCF7, and MCF10AT cell lines were treated with escalating doses of CCM in the presence or absence of $10 \mu \mathrm{M}$ DHA and analyzed by flow cytometry. Fold changes (A, C) were compared to respective cell line controls (without CCM or DHA). ${ }^{*} \mathrm{P}<0.05$ for Student's t-tests comparing the treatments with DHA to the treatments without DHA in three duplicate assays.

and CCM [53]. The fact that synergy is observable at low concentrations is of special interest in this case because while the antiproliferative effects of CCM alone may be more potent than those of DHA, CCM is known to be poorly absorbed and has been observed to remain under $2 \mu \mathrm{M}$ in the serum and urine of human subjects receiving several grams per day [74]. Conversely, DHA can achieve plasma concentrations of approximately $200 \mu \mathrm{M}$ in humans administered daily doses of oral DHA preparations over the course of a month [75]. These human subject data become especially interesting as we have demonstrated a DHA mediated enhancement of cellular CCM uptake. This means that when DHA and CCM are used in combination, the intracellular concentration of CCM achievable in vivo may not be limited to the concentration range previously observed. Careful, tissue-specific pharmacodynamics studies are needed to determine how our cell culture results can translate to a clinical setting, but the practical utility of this compound combination is promising.

As mentioned above, breast cancer is a collection of diseases with multiple phenotypes; therefore, one should not expect that a particular therapeutic agent will control every malignancy subtype. The fact that only the SK-BR-3 cell line was synergistically affected by DHA 
and CCM suggests specific breast cancer phenotype as an important factor for predicting efficacy. The ER ${ }^{-} /$ $\mathrm{Her}^{+}$phenotype is regarded as an aggressive tumorigenic phenotype. Our data suggest that molecular phenotype has specific implications for efficacy, and translation of these compounds into therapeutics will require extensive mechanistic studies. Beyond demonstrating the synergistic effect itself, the importance of this study lies in the demonstration that observed synergy is accompanied by cell signaling changes that are unique to the combination of the two compounds. A network state appears in which the aggregate of protein levels, protein states, and transcript levels are an emergent property of the combined presence of DHA and CCM.

The results shown in Figures 5 and 6 demonstrate that the synergistic effect of the CCM+DHA combination may in part be attributed to protein level effects described for CCM alone, but that are increased in the presence of DHA. CCM can increase the protein pool of PPAR $\gamma$ and increase phosphorylation of p53. Addition of DHA further increases both of these molecular effects and increases uptake of CCM by SK-BR-3 cells. This is interesting in that it fits a pattern observed for DHA in which it enhances the effects of other anti-cancer compounds: 5-fluorouracil on colon cancer cells [76], celecoxib on prostate cancer cells [77], and doxorubicin [78] in breast cancer. Our results, combined with previous studies, suggest that part of DHA's activity is to alter cellular permissiveness for uptake of several kinds of small organic molecules, possibly through alteration of membrane lipid composition. Uptake of CCM and DHA enhancement of this process were observed to be much stronger in SK-BR-3 cells relative to four other breast cancer cell lines, suggesting that the pharmacodynamics of the CCM+DHA combination may be dependent upon specific cancer phenotype, apart from the signaling changes that occur once the compounds actually enter a cell. Therefore, it is possible that the synergistic effect of CCM+DHA on SK-BR-3 cells is dependent specifically upon CCM uptake ability of this cell line, as opposed to its cellular receptor expression state, but further study of this distinction must account for the unique transcript-level regulation observed in the presence of CCM + DHA and not CCM alone. In this study we did not investigate the potential mechanism for CCM uptake by different breast cancer cell phenotypes, which is clearly a logical direction for our future studies.

Our microarray data suggest that cell cycle arrest and apoptosis include contributions from other events unique to the CCM+DHA combination upstream, downstream, or independent of PPAR $\gamma$ and phosphorylated p53. Two interaction networks were generated within the MetaCore (GeneGo) network analysis environment to illustrate all kinases documented as activators of p53 and all proteins documented to contribute to upregulation of PPAR $\gamma$ transcription (Additional file 7). From this it is clear that these two processes, while stimulated by CCM alone, can be upregulated through many alternate pathways. A 10-fold upregulation is seen for NLRP1, DUSP13 and UCHL1, all positively associated with apoptosis (see references in Additional file 8 for Figure 3) and all responding only to the CCM+DHA combination. Similar results are seen for genes associated with tumor suppression and MAP2, considered to be anti-metastatic. Downregulation is observed for genes associated with tumor progression, cell cycle progression, metastasis and anti-apoptosis/cell survival. Some of these were downregulated only when both DHA and CCM were applied to SK-BR-3 cells. Taken together, these results suggest multiple mechanisms in addition to enhanced CCM activity.

Two transcriptional responses of particular interest are CYP1B1 and SERPINB5. CYP1B1 was actually downregulated 2.4-fold by CCM alone, but this was reversed to 7.4-fold upregulation by the CCM+DHA combination (see Additional file 9 for Figure 3). DHA alone had no effect on this transcript. CYP1B1 is thought to contribute to the anti-proliferative effects of several dietary compounds by metabolizing them into products exhibiting additional cytotoxicity within cancer cells [69-72]. Presence of wild-type CYP1B1 was reported to be associated with protection against breast cancer in a population of Indian women [79]. SERPINB5, the protein product of which is also known as maspin, was upregulated 18.9-fold when SK-BR-3 cells were treated with $\mathrm{CCM}+\mathrm{DHA}$. Maspin is known to be upregulated by tamoxifen and is considered to be a downstream effector for the tumor suppression activity of tamoxifen [66-68]. It is, therefore, suggested that $\mathrm{CCM}+\mathrm{DHA}$ induces an anticancer effect through a mechanism that is shared by tamoxifen. Furthermore, SK-BR-3 cells are ER-, raising the question of whether the CCM+DHA combination can contribute to overcoming tamoxifen resistance.

The anti-proliferative effect of CCM+DHA on SK-BR3 cells is validated as a true synergy by molecular level characterization indicating that the emergent cell signaling network state is unique to the combined use of the two compounds. Transcript level responses are not an additive result of changes that would be predicted based upon activity of either compound alone. However, the functionally categorized heatmap blocks presented in Figure 3 are themselves only a beginning for the process of determining a mechanism of action. This preliminary analysis shows either transcript level changes that were strong in magnitude, for genes of some known functional description, or changes for which a direct connection with a process of interest is known, even if 
response was moderate. These transcriptional responses along with the synergistic antiproliferative effect demonstrated for SK-BR-3 cells are a compelling collection of disease relevant observations. However, the total genome-wide microarray data set requires network analysis on a scale beyond the scope of this study. Given the collection of strong transcript responses and the protein pool/activation responses of what can be considered two major signaling hubs (PPAR $\gamma$ and p53), the complete set of network nodes that mediate cellular response to $\mathrm{CCM}+\mathrm{DHA}$ is likely large and inclusive of multiple pathways. Construction of a working model and subsequent experimental dissection of that model requires a modular, carefully annotated assembly of molecular responses into network neighborhoods in which both interactive relationships and transcriptional response values can be visualized. In this way, transcriptional responses and changes in protein states can be studied for patterns of causation that suggest much more specific mechanistic hypotheses than are apparent in a static representation of expression data such as a heatmap. Additionally, the observation of synergy in only one of five different breast cancer cell phenotypes suggests that signal paths critical to cell proliferation are not uniformly accessible to the CCM+DHA combination in all breast cancer phenotypes. Determining the network of interacting nodes responsible for the SK-BR-3 response to $\mathrm{CCM}+\mathrm{DHA}$ should in turn reveal a set of signaling nodes that are candidates for being the root cause of phenotypic differences among breast cancer types.

\section{Conclusions}

Our data suggest that combination of DHA and curcumin may provide a novel, effective dietary supplemental treatment for some breast cancer patients, with a likely dependency upon molecular phenotype. It is important to stress that the synergistic antiproliferative effects were only observed in the SK-BR-3 cell line. Analysis of other breast cancer cell lines representing the $\mathrm{ER}^{-} \mathrm{PR}^{-}$ $\mathrm{HER}^{+}{ }^{+}$phenotype is required to confirm that the effect is related to cancer subtype and not solely a property of the SK-BR-3 cell line itself. In addition, there are breast cancer cell lines that match SK-BR-3 cells with respect to other characteristics (for example, expression of the luminal versus basal gene clusters) [11], and the possibility that a mechanistic explanation of synergy lies within these alternate characters is another immediate focus for extension of this work. DHA enhancement of cell permissiveness to curcumin uptake is one potential mechanism for the observed synergy. However, our microarray analysis suggests that some mechanistic pathways are triggered in the presence of the curcumin/ DHA combination and do not appear when either compound is used alone, indicating that at least part of the observed synergy is an emergent property of the combination specifically. Although this study, as conducted in an in vitro system, has certain limitations, a set of unique genes was identified for the synergistic effect of DHA and CCM. Studies in an in vivo system are currently underway to further validate the findings of the present study.

\section{Additional material}

\begin{abstract}
Additional file 1: Extracting three-replicate responsive genes from Miltenyi Biotec microarray data. The Excel file "Supplementary Data1.1.xIsx" demonstrates the first step in logical filtering of preselected candidate gene lists (PCGL) that are provided as pre-processed microarray data by Miltenyi Biotec. Each PCGL is a list of the microarray elements that returned a significant response within one replicate of a treatment (fold change $\geq 2$ and $P \leq 0.01$ ). Most transcripts (genes) are represented by more than one microarray element, and these do not always agree with each other, rendering the result for a gene ambiguous. Also, a single microarray address may not return the same result across all three replicates. Therefore, logical filters were implemented as conditional statements in Excel to compile a list, for each treatment, of only those genes that respond significantly in a consistent direction across three treatment replicates. Step one for the Zadd treatment (CCM+DHA) is presented as an example.
\end{abstract}

Additional file 2: Extracting identities of genes that did not respond to one treatment but did respond to another treatment. In order to assemble the heatmap in Figure 3, it was necessary for each gene to have a cell value across all three treatments, including those instances in which a particular gene had no response to a given treatment. The Excel file "Supplementary Data-1.2.xIsx" demonstrates, for the Zadd treatment, how to assemble the list of microarray elements that were isolated as three-replicate responders for either of the other two treatments, but that returned no significant response for all three replicates of the Zadd treatment. This list is used in the next step to query the raw data for Zadd in order to collect fold-change values for these elements.

Additional file 3: Extracting ratio, fold-change and $P$ values for genes that did not respond to one treatment but did respond to another treatment. The microarray element identities compiled in Supplementary Data-1.2 were then used in "Supplementary Data-1.3.xIsx" to query the gene ratio lists (comprehensive data for all microarray elements) for each replicate of the Zadd treatment. Results for each element are compiled into a single final data set sorted by element ID.

Additional file 4: Mean ratio, fold-change and $\mathrm{P}$ values for "ALL not Zadd" microarray element list, checked against three-replicate responders for Zadd. In the Excel file "Supplementary Data 1.4.xIsx", mean ratio, mean fold-change and mean $P$ values are calculated for all microarray elements compiled in Supplementary Data-1.2. These are then sorted by gene ID, and each gene is represented by the microarray element returning the lowest mean $P$ value. This list of genes is then checked against Zadd three-replicate responders in order to catch disagreement among microarray elements.

Additional file 5: Final set of Zadd gene responses for all genes that responded to any of the three treatments. This final data set contains treatment/control ratios, fold-change values and $P$ values, from Zadd treatment replicates, for all transcripts that responded $\geq 2$-fold, $\mathrm{P} \leq$ 0.01 , in any of the three treatments. For any transcript that was not a three-replicate responder in the Zadd treatment, values were derived as described in Supplementary Data 1.1-1.4. The set of values in Excel file "Supplementary Data 1.5.xlsx" served as the source of transcript response values for Zadd in Figure 3. Transcript responses used in Figure 3 for each of the other two treatments, CCM and DHA, were derived using the same workflow.

Additional file 6: Distribution of fold change by treatment for whole human genome transcript analysis. This figure represents the raw distribution of fold change magnitude for all transcripts that 
exhibited fold change $\geq 2.0(p<0.01)$ in all three replicates of at least one treatment.

Additional file 7: Possible routes to phosphorylation of $\mathrm{p} 53$ and upregulated transcription of PPAR $\boldsymbol{\gamma}$. p53 and PPAR $\gamma$ were each used as single beginning nodes around which to build one-step expansion networks within MetaCore ${ }^{\mathrm{TM}^{\mathrm{TM}}}$ version 6.3 (GeneGo).

Additional file 8: Literature annotation for transcript functional categories in Figure 3. Numbered references included in this file match reference numbers appearing to the right of each HGNC symbol in Figure 3

Additional file 9: Data represented by Figure 3. Fold change values and associated P-values for transcripts represented in Figure 3.

\section{Abbreviations}

DHA: docosahexaenoic acid; CCM: curcumin; PPAR: peroxisome proliferatoractivated receptor; ER: estrogen receptor; PCGL: preselected candidate gene lists; MBGS: Miltenyi Biotec Genomics Services.

\section{Acknowledgements}

The authors would like to thank Dr. Cary Mariash for technical assistance and helpful discussions. This study was funded by NIH RO3CA137765-01A1 (RAS) and a grant from the Showalter Trust (JDA).

\section{Author details}

${ }^{1}$ Cellular Biochemistry Laboratory, Methodist Research Institute, Indiana University Health, Indianapolis, Indiana, USA. ${ }^{2}$ Laboratory for Chemical Biology and Drug Development Bindley Bioscience Center, Discovery Park, Purdue University, West Lafayette, Indiana, USA. ${ }^{3}$ Department of Biology, Indiana University-Purdue University, Indianapolis, Indiana, USA. ${ }^{4}$ Department of Medicine, Indiana University School of Medicine, Indianapolis, Indiana, USA.

\section{Authors' contributions}

JDA performed experiments, participated in the experimental design, and drafted the manuscript. AAB performed analysis of the microarray results and helped to draft the manuscript. CT participated in the design of experiments, performed statistical analysis and helped to draft the manuscript. $\mathrm{KH}$ performed immunoassays and participated in the experimental design. JFV performed immunoassays and HPLC experiments. ZX performed HPLC experiments, analyzed HPLC results, and helped to draft the manuscript. VJD participated in experimental design and helped to draft the manuscript. RAS conceived of the study, and participated in its design and coordination and helped to draft the manuscript. All authors read and approved the final manuscript.

\section{Competing interests}

The authors declare that they have no competing interests.

Received: 26 January 2011 Accepted: 21 April 2011

Published: 21 April 2011

\section{References}

1. Aitken SJ, Thomas JS, Langdon SP, Harrison DJ, Faratian D: Quantitative analysis of changes in ER, PR and HER2 expression in primary breast cancer and paired nodal metastases. Ann Oncol 21(6):1254-1261.

2. Bauer K, Parise C, Caggiano V: Use of ER/PR/HER2 subtypes in conjunction with the 2007 St Gallen Consensus Statement for early breast cancer. BMC Cancer 10:228.

3. Henriksen $\mathrm{KL}$, Rasmussen BB, Lykkesfeldt AE, Moller S, Ejlertsen B, Mouridsen HT: An ER activity profile including ER, PR, BCl-2 and IGF-IR may have potential as selection criterion for letrozole or tamoxifen treatment of patients with advanced breast cancer. Acta Oncol 2009, 48(4):522-531.

4. Lambein K, Praet M, Forsyth R, Van den Broecke R, Braems G, Matthys B, Cocquyt $V$, Denys $H$, Pauwels $P$, Libbrecht $L$ : Relationship between pathological features, HER2 protein expression and HER2 and CEP17 copy number in breast cancer: biological and methodological considerations. J Clin Pathol 64(3):200-207.

5. Parise CA, Bauer KR, Brown MM, Caggiano V: Breast cancer subtypes as defined by the estrogen receptor (ER), progesterone receptor (PR), and the human epidermal growth factor receptor 2 (HER2) among women with invasive breast cancer in California, 1999-2004. Breast J 2009, 15(6):593-602.

6. Boyd ZS, Wu QJ, O'Brien C, Spoerke J, Savage H, Fielder PJ, Amler L, Yan Y, Lackner MR: Proteomic analysis of breast cancer molecular subtypes and biomarkers of response to targeted kinase inhibitors using reversephase protein microarrays. Mol Cancer Ther 2008, 7(12):3695-3706.

7. Chen XS, Wu JY, Huang O, Chen CM, Wu J, Lu JS, Shao ZM, Shen ZZ, Shen KW: Molecular subtype can predict the response and outcome of Chinese locally advanced breast cancer patients treated with preoperative therapy. Oncol Rep 23(5):1213-1220.

8. Kurt M, Harputluoglu H, Dede DS, Gullu IH, Altundag K: Potential molecular targeted therapies in the management of the basal-like subtype of breast cancer. Breast 2007, 16(2):111-112.

9. Schlotter $\mathrm{CM}$, Vogt $\mathrm{U}$, Allgayer $\mathrm{H}$, Brandt B: Molecular targeted therapies for breast cancer treatment. Breast Cancer Res 2008, 10(4):211.

10. Singh S, Shi Q, Bailey ST, Palczewski MJ, Pardee AB, Iglehart JD, Biswas DK: Nuclear factor-kappaB activation: a molecular therapeutic target for estrogen receptor-negative and epidermal growth factor receptor family receptor-positive human breast cancer. Mol Cancer Ther 2007, 6(7):1973-1982.

11. Neve RM, Chin K, Fridlyand J, Yeh J, Baehner FL, Fevr T, Clark L, Bayani N, Coppe JP, Tong F, et al: A collection of breast cancer cell lines for the study of functionally distinct cancer subtypes. Cancer Cell 2006, 10(6):515-527.

12. Stillwell W, Wassall SR: Docosahexaenoic acid: membrane properties of a unique fatty acid. Chem Phys Lipids 2003, 126(1):1-27.

13. Berg JP, Glattre E, Haldorsen T, Hostmark AT, Bay IG, Johansen AF, Jellum E: Longchain serum fatty acids and risk of thyroid cancer: a populationbased case-control study in Norway. Cancer Causes Control 1994, 5(5):433-439.

14. Kaizer L, Boyd NF, Kriukov V, Tritchler D: Fish consumption and breast cancer risk: an ecological study. Nutr Cancer 1989, 12(1):61-68.

15. Schloss I, Kidd MS, Tichelaar HY, Young GO, O'Keefe SJ: Dietary factors associated with a low risk of colon cancer in coloured west coast fishermen. S Afr Med J 1997, 87(2):152-158.

16. Vogel VG, McPherson RS: Dietary epidemiology of colon cancer. Hematol Oncol Clin North Am 1989, 3(1):35-63.

17. Connolly JM, Gilhooly EM, Rose DP: Effects of reduced dietary linoleic acid intake, alone or combined with an algal source of docosahexaenoic acid, on MDA-MB-231 breast cancer cell growth and apoptosis in nude mice. Nutr Cancer 1999, 35(1):44-49.

18. Rose DP: The mechanistic rationale in support of dietary cancer prevention. Prev Med 1996, 25(1):34-37.

19. Rose DP, Connolly JM: Antiangiogenicity of docosahexaenoic acid and its role in the suppression of breast cancer cell growth in nude mice. Int J Oncol 1999, 15(5):1011-1015.

20. Wu M, Harvey KA, Ruzmetov N, Welch ZR, Sech L, Jackson K, Stillwell W, Zaloga GP, Siddiqui RA: Omega-3 polyunsaturated fatty acids attenuate breast cancer growth through activation of a neutral sphingomyelinasemediated pathway. Int J Cancer 2005, 117(3):340-348.

21. Blanckaert V, Ulmann L, Mimouni V, Antol J, Brancquart L, Chenais B Docosahexaenoic acid intake decreases proliferation, increases apoptosis and decreases the invasive potential of the human breast carcinoma cell line MDA-MB-231. Int J Oncol 36(3):737-742.

22. Chiu LC, Wong EY, Ooi VE: Docosahexaenoic acid modulates different genes in cell cycle and apoptosis to control growth of human leukemia HL-60 cells. Int J Oncol 2004, 25(3):737-744.

23. Kim MS, Kang HJ, Moon A: Inhibition of invasion and induction of apoptosis by curcumin in H-ras-transformed MCF10A human breast epithelial cells. Arch Pharm Res 2001, 24(4):349-354.

24. Kim HJ, Vosseler CA, Weber PC, Erl W: Docosahexaenoic acid induces apoptosis in proliferating human endothelial cells. J Cell Physiol 2005, 204(3):881-888.

25. Miura Y, Takahara K, Murata Y, Utsumi K, Tada M, Takahata K: Docosahexaenoic acid induces apoptosis via the Bax-independent pathway in HL-60 cells. Biosci Biotechnol Biochem 2004, 68(11):2415-2417. 
26. Serini S, Trombino S, Oliva F, Piccioni E, Monego G, Resci F, Boninsegna A, Picci N, Ranelletti FO, Calviello G: Docosahexaenoic acid induces apoptosis in lung cancer cells by increasing MKP-1 and down-regulating p-ERK1/2 and p-p38 expression. Apoptosis 2008, 13(9):1172-1183.

27. Yamagami T, Porada CD, Pardini RS, Zanjani ED, Almeida-Porada G: Docosahexaenoic acid induces dose dependent cell death in an early undifferentiated subtype of acute myeloid leukemia cell line. Cancer Biol Ther 2009, 8(4):331-337.

28. Siddiqui RA, Jenski LJ, Harvey KA, Wiesehan JD, Stillwell W, Zaloga GP: Cellcycle arrest in Jurkat leukaemic cells: a possible role for docosahexaenoic acid. Biochem J 2003, 371(Pt 2):621-629.

29. Fan YY, Spencer TE, Wang N, Moyer MP, Chapkin RS: Chemopreventive n-3 fatty acids activate RXRalpha in colonocytes. Carcinogenesis 2003, 24(9):1541-1548

30. Tanaka T, Suh KS, Lo AM, De Luca LM: p21WAF1/CIP1 is a common transcriptional target of retinoid receptors: pleiotropic regulatory mechanism through retinoic acid receptor (RAR)/retinoid $\times$ receptor (RXR) heterodimer and RXR/RXR homodimer. J Biol Chem 2007. 282(41):29987-29997.

31. Altenburg JD, Siddiqui RA: Omega-3 polyunsaturated fatty acids downmodulate CXCR4 expression and function in MDA-MB-231 breast cancer cells. Mol Cancer Res 2009, 7(7):1013-1020.

32. Srimal RC, Dhawan BN: Pharmacology of diferuloyl methane (curcumin), a non-steroidal anti-inflammatory agent. J Pharm Pharmacol 1973, 25(6):447-452.

33. Maheshwari RK, Singh AK, Gaddipati J, Srimal RC: Multiple biological activities of curcumin: a short review. Life Sci 2006, 78(18):2081-2087.

34. Lopez-Lazaro M: Anticancer and carcinogenic properties of curcumin: considerations for its clinical development as a cancer chemopreventive and chemotherapeutic agent. Mol Nutr Food Res 2008, 52(Suppl 1): S103-127.

35. Padhye S, Chavan D, Pandey S, Deshpande J, Swamy KV, Sarkar FH: Perspectives on chemopreventive and therapeutic potential of curcumin analogs in medicinal chemistry. Mini Rev Med Chem 10(5):372-387.

36. Patel BB, Majumdar AP: Synergistic role of curcumin with current therapeutics in colorectal cancer: minireview. Nutr Cancer 2009, 61(6):842-846.

37. Villegas I, Sanchez-Fidalgo S, Alarcon de la Lastra C: New mechanisms and therapeutic potential of curcumin for colorectal cancer. Mol Nutr Food Res 2008, 52(9):1040-1061.

38. Shishodia S, Chaturvedi MM, Aggarwal BB: Role of curcumin in cancer therapy. Curr Probl Cancer 2007, 31(4):243-305.

39. Chen A, Xu J, Johnson AC: Curcumin inhibits human colon cancer cell growth by suppressing gene expression of epidermal growth factor receptor through reducing the activity of the transcription factor Egr-1. Oncogene 2006, 25(2):278-287.

40. Perkins S, Verschoyle RD, Hill K, Parveen I, Threadgill MD, Sharma RA, Williams ML, Steward WP, Gescher AJ: Chemopreventive efficacy and pharmacokinetics of curcumin in the $\mathrm{min} /+$ mouse, a model of familial adenomatous polyposis. Cancer Epidemiol Biomarkers Prev 2002, 11(6):535-540.

41. Huang MT, Lou YR, Ma W, Newmark HL, Reuhl KR, Conney AH: Inhibitory effects of dietary curcumin on forestomach, duodenal, and colon carcinogenesis in mice. Cancer Res 1994, 54(22):5841-5847.

42. Singh SV, Hu X, Srivastava SK, Singh M, Xia H, Orchard JL, Zaren HA: Mechanism of inhibition of benzo[a]pyrene-induced forestomach cancer in mice by dietary curcumin. Carcinogenesis 1998, 19(8):1357-1360.

43. Dorai T, Dutcher JP, Dempster DW, Wiernik PH: Therapeutic potential of curcumin in prostate cancer-V: Interference with the osteomimetic properties of hormone refractory $\mathrm{C} 4-2 \mathrm{~B}$ prostate cancer cells. Prostate 2004, 60(1):1-17.

44. Choudhuri T, Pal S, Das T, Sa G: Curcumin selectively induces apoptosis in deregulated cyclin D1-expressed cells at G2 phase of cell cycle in a p53dependent manner. J Biol Chem 2005, 280(20):20059-20068.

45. Thangapazham RL, Sharma A, Maheshwari RK: Multiple molecular targets in cancer chemoprevention by curcumin. Aaps J 2006, 8(3):E443-449.

46. Aggarwal BB, Banerjee S, Bharadwaj U, Sung B, Shishodia S, Sethi G: Curcumin induces the degradation of cyclin $E$ expression through ubiquitin-dependent pathway and up-regulates cyclin-dependent kinase inhibitors p21 and p27 in multiple human tumor cell lines. Biochem Pharmacol 2007, 73(7):1024-1032.
47. Notoya M, Nishimura H, Woo JT, Nagai K, Ishihara $Y$, Hagiwara H: Curcumin inhibits the proliferation and mineralization of cultured osteoblasts. Eur $J$ Pharmacol 2006, 534(1-3):55-62.

48. Park MJ, Kim EH, Park IC, Lee HC, Woo SH, Lee JY, Hong YJ, Rhee CH, Choi SH, Shim BS, et al: Curcumin inhibits cell cycle progression of immortalized human umbilical vein endothelial (ECV304) cells by upregulating cyclin-dependent kinase inhibitor, p21WAF1/CIP1, p27KIP1 and p53. Int J Oncol 2002, 21(2):379-383.

49. Zheng $\mathrm{S}$, Chen A: Activation of PPARgamma is required for curcumin to induce apoptosis and to inhibit the expression of extracellular matrix genes in hepatic stellate cells in vitro. Biochem J 2004, 384(Pt 1):149-157.

50. Chen YR, Tan TH: Inhibition of the c-Jun N-terminal kinase (JNK) signaling pathway by curcumin. Oncogene 1998, 17(2):173-178

51. Choudhuri T, Pal S, Agwarwal ML, Das T, Sa G: Curcumin induces apoptosis in human breast cancer cells through p53-dependent Bax induction. FEBS Lett 2002, 512(1-3):334-340.

52. Squires MS, Hudson EA, Howells L, Sale S, Houghton CE, Jones JL, Fox LH, Dickens M, Prigent SA, Manson MM: Relevance of mitogen activated protein kinase (MAPK) and phosphotidylinositol-3-kinase/protein kinase $\mathrm{B}$ (PI3K/PKB) pathways to induction of apoptosis by curcumin in breast cells. Biochem Pharmacol 2003, 65(3):361-376.

53. Saw $C L$, Huang $Y$, Kong AN: Synergistic anti-inflammatory effects of low doses of curcumin in combination with polyunsaturated fatty acids: docosahexaenoic acid or eicosapentaenoic acid. Biochem Pharmacol 79(3):421-430.

54. Swamy MV, Citineni B, Patlolla JM, Mohammed A, Zhang Y, Rao CV: Prevention and treatment of pancreatic cancer by curcumin in combination with omega-3 fatty acids. Nutr Cancer 2008, 60(Suppl 1):81-89.

55. Bowe DB, Sadlonova A, Toleman CA, Novak Z, Hu Y, Huang P, Mukherjee S, Whitsett T, Frost AR, Paterson AJ, et al: O-GIcNAc integrates the proteasome and transcriptome to regulate nuclear hormone receptors. Mol Cell Biol 2006, 26(22):8539-8550.

56. Heppner GH, Wolman SR: MCF-10AT: A Model for Human Breast Cancer Development. Breast J 1999, 5(2):122-129.

57. Shekhar PV, Chen ML, Werdell J, Heppner GH, Miller FR, Christman JK. Transcriptional activation of functional endogenous estrogen receptor gene expression in MCF10AT cells: a model for early breast cancer. Int J Oncol 1998, 13(5):907-915.

58. Subik K, Lee JF, Baxter L, Strzepek T, Costello D, Crowley P, Xing L, Hung MC, Bonfiglio T, Hicks DG, et al: The Expression Patterns of ER, PR, HER2, CK5/6, EGFR, Ki-67 and AR by Immunohistochemical Analysis in Breast Cancer Cell Lines. Breast Cancer (Auckl) 4:35-41.

59. Tallarida RJ, Stone DJ Jr, Raffa RB: Efficient designs for studying synergistic drug combinations. Life Sci 1997, 61(26):PL 417-425.

60. Rodbard D: Apparent positive cooperative effects in cyclic AMP and corticosterone production by isolated adrenal cells in response to ACTH analogues. Endocrinology 1974, 94(5):1427-1437.

61. Lee JJ, Kong M, Ayers GD, Lotan R: Interaction index and different methods for determining drug interaction in combination therapy. $J$ Biopharm Stat 2007, 17(3):461-480.

62. Weng L, Dai H, Zhan Y, He Y, Stepaniants SB, Bassett DE: Rosetta error model for gene expression analysis. Bioinformatics 2006, 22(9):1111-1121.

63. Chignell CF, Bilski P, Reszka KJ, Motten AG, Sik RH, Dahl TA: Spectral and photochemical properties of curcumin. Photochem Photobiol 1994, 59(3):295-302.

64. Kunwar A, Barik A, Mishra B, Rathinasamy K, Pandey R, Priyadarsini Kl: Quantitative cellular uptake, localization and cytotoxicity of curcumin in normal and tumor cells. Biochim Biophys Acta 2008, 1780(4):673-679.

65. Shankavaram UT, Reinhold WC, Nishizuka S, Major S, Morita D, Chary KK, Reimers MA, Scherf U, Kahn A, Dolginow D, et al: Transcript and protein expression profiles of the $\mathrm{NCl}-60$ cancer cell panel: an integromic microarray study. Mol Cancer Ther 2007, 6(3):820-832.

66. Bailey CM, Khalkhali-Ellis Z, Seftor EA, Hendrix MJ: Biological functions of maspin. J Cell Physiol 2006, 209(3):617-624.

67. Khalkhali-Ellis Z, Christian AL, Kirschmann DA, Edwards EM, RezaieThompson M, Vasef MA, Gruman LM, Seftor RE, Norwood LE, Hendrix MJ: Regulating the tumor suppressor gene maspin in breast cancer cells: a potential mechanism for the anticancer properties of tamoxifen. Clin Cancer Res 2004, 10(2):449-454. 
68. Liu Z, Shi HY, Nawaz Z, Zhang M: Tamoxifen induces the expression of maspin through estrogen receptor-alpha. Cancer Lett 2004, 209(1):55-65

69. Androutsopoulos VP, Mahale S, Arroo RR, Potter G: Anticancer effects of the flavonoid diosmetin on cell cycle progression and proliferation of MDA-MB 468 breast cancer cells due to CYP1 activation. Oncol Rep 2009, 21(6):1525-1528

70. Androutsopoulos VP, Ruparelia K, Arroo RR, Tsatsakis AM, Spandidos DA: CYP1-mediated antiproliferative activity of dietary flavonoids in MDAMB-468 breast cancer cells. Toxicology 2009, 264(3):162-170.

71. Ware WR: Nutrition and the prevention and treatment of cancer: association of cytochrome P450 CYP1B1 with the role of fruit and fruit extracts. Integr Cancer Ther 2009, 8(1):22-28.

72. Ware WR: P450 CYP1B1 mediated fluorescent tumor markers: a potentially useful approach for photodynamic therapy, diagnosis and establishing surgical margins. Med Hypotheses 2009, 72(1):67-70.

73. Cheah YH, Nordin FJ, Sarip R, Tee TT, Azimahtol HL, Sirat HM, Rashid BA, Abdullah NR, Ismail Z: Combined xanthorrhizol-curcumin exhibits synergistic growth inhibitory activity via apoptosis induction in human breast cancer cells MDA-MB-231. Cancer Cell Int 2009, 9:1.

74. Cheng AL, Hsu CH, Lin JK, Hsu MM, Ho YF, Shen TS, Ko JY, Lin JT, Lin BR, Ming-Shiang W, et al: Phase I clinical trial of curcumin, a chemopreventive agent, in patients with high-risk or pre-malignant lesions. Anticancer Res 2001, 21(4B):2895-2900.

75. Rusca A, Di Stefano AF, Doig MV, Scarsi C, Perucca E: Relative bioavailability and pharmacokinetics of two oral formulations of docosahexaenoic acid/eicosapentaenoic acid after multiple-dose administration in healthy volunteers. Eur J Clin Pharmacol 2009, 65(5):503-510.

76. Calviello G, Di Nicuolo F, Serini S, Piccioni E, Boninsegna A, Maggiano N, Ranelletti FO, Palozza P: Docosahexaenoic acid enhances the susceptibility of human colorectal cancer cells to 5 -fluorouracil. Cancer Chemother Pharmacol 2005, 55(1):12-20.

77. Narayanan NK, Narayanan BA, Bosland M, Condon MS, Nargi D: Docosahexaenoic acid in combination with celecoxib modulates HSP70 and p53 proteins in prostate cancer cells. Int J Cancer 2006 119(7):1586-1598.

78. Bougnoux P, Hajjaji N, Ferrasson MN, Giraudeau B, Couet C, Le Floch O: Improving outcome of chemotherapy of metastatic breast cancer by docosahexaenoic acid: a phase II trial. Br J Cancer 2009, 101(12):1978-1985.

79. Yadav S, Singhal NK, Singh V, Rastogi N, Srivastava PK, Singh MP: Association of single nucleotide polymorphisms in CYP1B1 and COMT genes with breast cancer susceptibility in Indian women. Dis Markers 2009, 27(5):203-210.

\section{Pre-publication history}

The pre-publication history for this paper can be accessed here: http://www.biomedcentral.com/1471-2407/11/149/prepub

doi:10.1186/1471-2407-11-149

Cite this article as: Altenburg et al:: A synergistic antiproliferation effect of curcumin and docosahexaenoic acid in SK-BR-3 breast cancer cells: unique signaling not explained by the effects of either compound alone. BMC Cancer 2011 11:149.

\section{Submit your next manuscript to BioMed Central and take full advantage of:}

- Convenient online submission

- Thorough peer review

- No space constraints or color figure charges

- Immediate publication on acceptance

- Inclusion in PubMed, CAS, Scopus and Google Scholar

- Research which is freely available for redistribution

Submit your manuscript at www.biomedcentral.com/submit 